\title{
HUBUNGAN PENGETAHUAN INFEKSI NOSOKOMIAL TERHADAP KEPATUHAN HAND HYGIENE PERAWAT BIDAN DI RUANG RAWAT INAP RUMAH SAKIT MITRA HUSADA \\ NOSOKOMIAL INFECTION KNOWLEDGE CONNECTION TO COMPLIANCE HAND HYGIENE NURSE AND MIDWIFEIN INTERRUPTED ROOMMITRA HUSADA HOSPITAL
}

\author{
FitraPringgayuda $^{1}$, Desi Ari Madiyanti ${ }^{2}$, Nurdianto $^{3}$ \\ ${ }^{1,2,3}$ STIKes Muhammadiyah Pringsewu, \\ e-mail: fpringgayuda@yahoo.com
}

\begin{abstract}
ABSTRAK
Pengetahuan perawat tentang infeksi nosokomial dan pencegahannya merupakan stimulasi sosial dari luar yang dapat menimbulkan respon emosional perawat terhadap upaya universal precaution yang akan meningkatkan upaya pencegahan infeksi nosokomial. Menjaga kebersihan tangan dengan baik dapat mencegah penularan mikroorganisme dan menurunkan infeksi nosokomial. Tujuan untuk melihat hubungan kepatuhan infeksi nosokomial terhadap kepatuhan handhygiene perawat bidan di ruang rawat inap RS. Mitra Husada. Jenis penelitian yang digunakan adalah dengan menggunakan desain penelitian deskriptif korelasi. Pada penelitian ini jumlah sampel yang diambil adalah sebanyak 34 orang dengan menggunakan tekhnik stratified random sampling. Hasil uji statistik penelitian diperoleh $p$-value sebesar 0,016 (lebih kecil dari nilai alpha $=0,05$ ) yang berarti Ha diterima sehingga disimpulkan ada hubungan yang bermakna (signifikan) antara hubungan pengetahuan infeksi nosokomial dengan kepatuhan handhygiene dalam 5 momen di ruang rawat inap RS. Mitra Husada. Hasil uji statistik diperoleh $p$ - value sebesar 0,045 (lebih kecil dari nilai alpha $=0,05$ ) yang berarti Ha diterima sehingga disimpulkan ada hubungan yang bermakna (signifikan) antara hubungan pengetahuan infeksi nosokomial dengan kepatuhan prosedur handhygiene di ruang rawat inap RS. Mitra Husada.
\end{abstract}

Kata kunci: pengetahuan infeksi nosokomial, kepatuhan handhygiene

\begin{abstract}
Nurse's knowledge of nosocomial infection and its prevention is external social stimulation that can lead to nurse emotional responses to universal precaution efforts that will increase the prevention of nosocomial infection. Maintaining good handhygiene can prevent transmission of microorganism and reduce nosocomial infections. Aim of this study was to observe the correlation between nosocomial infection adherence to midwife nurse handhygiene in Mitra Husada Hospital. In this study the number of samples taken is as many as 34 people with uses stratified random sampling. Result of the statistical test of the research obtained p-value equal to 0,016 (smaller than alpha value $=0,05$ ) meaning $\mathrm{Ha}$ accepted so concluded there is significant relation between knowledge relation of nosocomial infection with handhygiene compliance in 5 moment in inpatient room Mitra Husada Hospital. The result of statistical test obtained p-value equalto 0,045 (less than alpha value $=0,05$ ) meaning Ha accepted so concluded there is significant relation between knowledge relation of nosocomial infection with compliance of handhygiene procedure at Mitra husada Ward hospital.
\end{abstract}

Keywords: knowledge of nosocomial infection, handhygiene compliance 


\section{PENDAHULUAN}

Infeksi nosokomial masih menjadi masalah utama dalam dunia. Data surveilans World Health Organization (WHO) infeksi nasocomial sebesar 5\% pertahun. Indonesia menyebutkan bahwa di RS Cipto Mangunkusumo, Inos mencapai $0-14,4 \%{ }^{1}$. Petugas kesehatan mempunyai peran besar dalam rantai transmisi infeksi ini $^{2}$, salah satu penyebab bermacam penyakit yang bisa berasal dari penderita, petugas kesehatan, dan lingkungan ${ }^{3}$. Peran perawat dalam pencegahan infeksi nosokomial sangat penting karena dapat menjadi sumber utama terpapar infeksi nosokomial ${ }^{3}$.

Setiap pasien mempunyai hak untuk mendapatkan keamanan dan keselamatan. Berdasarkan KEMKES No.129 tahun 2008, kejadian infeksi nosokomial menjadi salah satu pedoman mutu pelayanan rumah sakit ${ }^{4}$. Perilaku handhygiene perawat merupakan salah satu faktornya. Menurut data RISKESDAS 2013, pravalensi nasional kepatuhan handhygiene adalah 23,2\% . Menjaga kebersihan tangan dengan baik dapat mencegah penularan mikroorganisme dan menurunkan infeksi nosokomial ${ }^{5}$. WHO mencetuskan global patient safety challenge dengan clean care is safe care pada tahun 2009, dan merumuskan inovasi strategi penerapan handhygiene untuk petugas kesehatan dengan my five momments for handhygiene ${ }^{7}$.
Pelaksanaan cuci tangan hanya sekitar $40 \%$ $50 \%$ pada petugas kesehatan ${ }^{8}$. Secara umum, petugas kesehatan mengetahui tentang pentingnya handhygiene dalam mencegah infeksi namun pada pada pelaksanaan cuci tangan yang sesuai dengan prosedur masih rendah pada petugas kesehatan ${ }^{9}$. Rendahnya pelaksanaan cuci tangan petugas kesehatan dipengaruhi oleh faktor ketidaktahuan petugas kesehatan tangan dapat terkontaminasi menjadi alasan mengapa pelaksanaan cuci tangan masih rendah ${ }^{10}$.

Wawancara November 2016 dengan tim PPIRS, perawat dan bidan yang masih belum melakukan cuci tangan sesuai dengan Standar Prosedur Operasional (SPO). Observasi diperoleh data dari 190 terdapat 62 orang tidak mencuci tangan sesuai SPO. Kebersihan tangan 5 moment mencapai $54,41 \%$. Sebelum kontak (47,5\%), setelah kontak dengan pasien $(70,83 \%)$. Data menunjukkan bahwa angka kepatuhan petugas dalam melakukan kebersihan tangan belum sesuai target yang diharapkan yakni $80 \%$.

\section{METODE}

Penelitian ini menggunakan desain penelitian deskriptif korelasi ${ }^{8}$. Peneliti menggunakan desain ini untuk mengetahui hubungan pengetahuan infeksi nosokomial terhadap kepatuhan handhygiene perawat dan bidan di ruang rawat inap. Populasi pada penelitian ini adalah perawat dan bidan. Sampel 34 orang menggunakan metode stratified random 
sampling 9 . Pengumpulan data dilakukan dengan Wawancara semi terstruktur kepada responden menggunakan pedoman wawancara. Observasi untuk melihat apakah petugas tenaga Kesehatan melakukan kepatuhan handhygiene atau tidak. Pengisian kuisioner untuk memperoleh data statistik mengenai hubungan pengetahuan infeksi nosokomial terhadap kepatuhan handhygiene perawat bidan. Pengumpulan data dilakukan oleh peneliti dan dibantu kepala ruangan.

\section{HASIL}

\section{Tabel 1}

Karakteristik Responden Berdasarkan Usia dan Jenis Kelamin Responden

\begin{tabular}{lll}
\hline \multirow{2}{*}{ Karakteristik } & Jumlah \\
\cline { 2 - 3 } & Frek & \% \\
\hline Usia & & \\
25 tahun & 6 & $17,6 \%$ \\
26 tahun & 4 & $11,8 \%$ \\
27 tahun & 6 & $17,6 \%$ \\
28 tahun & 7 & $20,6 \%$ \\
29 tahun & 5 & $14,7 \%$ \\
30 tahun & 6 & $17,6 \%$ \\
Jenis Kelamin & & \\
Laki-laki & 19 & $55,9 \%$ \\
Perempuan & 15 & $44,1 \%$ \\
& & \\
\hline
\end{tabular}

Berdasarkan tabel 1 diatas menunjukkan distribusi frekuensi responden penelitian berdasarkan usia responden, terdapat 20,6\% responden yang berumur 28 tahun dan terdapat $55,9 \%$ responden yang berjenis kelamin laki-laki dan terdapat $44,1 \%$ responden yang berjenis kelamin perempuan.

Tabel 2

Distribusi Frekuensi Responden Berdasarkan Pengetahuan Infeksi Nosokomial

\begin{tabular}{lcc}
\hline \multirow{2}{*}{ Karakteristik } & \multicolumn{2}{c}{ Jumlah } \\
\cline { 2 - 3 } & Frek & \% \\
\hline Pengetahuan & & \\
Infeksi & & \\
Nosokomial & & \\
Baik & 19 & $55,9 \%$ \\
Tidak Baik & 15 & $44,1 \%$ \\
\hline
\end{tabular}

Tabel 2 menunjukkan distribusi frekuensi responden berdasarkan pengetahuan mengenai infeksi nosokomial. Terdapat $55,9 \%$ responden yang memiliki pengetahuan baik.

Tabel 3

Distribusi Frekuensi Responden Berdasarkan Kepatuhan Hand Hygiene 5 Momen

\begin{tabular}{lcc}
\hline \multirow{2}{*}{ Karakteristik } & \multicolumn{2}{c}{ Jumlah } \\
\cline { 2 - 3 } & Frek & \% \\
\hline Kepatuhan & & \\
handhygiene & & \\
5 moment & & \\
Patuh & 26 & $76,5 \%$ \\
Tidak Patuh & 8 & $23,5 \%$ \\
\hline
\end{tabular}

Tabel 3 menunjukkan distribusi frekuensi responden berdasarkan kepatuhan handhygiene5 momen. Terdapat 76,5\% responden yang patuh. 
Tabel 4

Distribusi Frekuensi Responden Berdasarkan Kepatuhan Prosedur HandHygiene

\begin{tabular}{ccc}
\hline Karakteristik & Frekwensi & $\%$ \\
\hline Patuh & 19 & $55,9 \%$ \\
Tidak Patuh & 15 & $44,1 \%$ \\
\hline
\end{tabular}

Tabel 4 menunjukkan distribusi frekuensi responden berdasarkan kepatuhan prosedur handhygiene. Terdapat $55,9 \%$ responden yang patuh.

Tabel. 5

Pengetahuan Infeksi Nosokomial Memiliki Hubungan terhadap Kepatuhan Hand HygienePerawat Bidan dalam 5 Momen

\begin{tabular}{|c|c|c|c|c|c|c|c|c|}
\hline \multirow{2}{*}{\begin{tabular}{l}
\multicolumn{1}{c}{ Variabel } \\
Pengetahuan \\
Infeksi \\
Nasokomial
\end{tabular}} & \multicolumn{4}{|c|}{$\begin{array}{l}\text { Kepatuhan handhygiene } \\
\text { perawat bidan } 5 \text { moment }\end{array}$} & \multicolumn{2}{|c|}{ Total } & \multirow[t]{2}{*}{ p-value } & \multirow[t]{2}{*}{ OR 95\% CI } \\
\hline & \multicolumn{2}{|c|}{ Patuh } & \multicolumn{2}{|c|}{ Tidak patuh } & & & & \\
\hline & $\mathrm{N}$ & $\%$ & $\mathrm{~N}$ & $\%$ & $\mathrm{~N}$ & $\%$ & & \\
\hline Baik & 18 & 94,7 & 1 & 5,3 & 19 & 100 & 0,016 & $\begin{array}{c}15,750 \\
; 52-150,141\end{array}$ \\
\hline Tidak baik & 8 & 53,3 & 7 & 46,7 & 15 & 100 & & \\
\hline Total & 26 & 76,5 & 8 & 23,5 & 34 & 100 & & \\
\hline
\end{tabular}

Sumber: Data Primer, 2017

Berdasarkan tabel 5 diatas diketahui bahwa ada sebanyak $94,7 \%$ responden yang memiliki pengetahuan yang baik dan patuh dalam melakukan hand hygiene dalam 5 momen, sedangkan responden memiliki pengetahuan tidak baik dan tidak patuh dalam melakukan hand hygiene dalam 5 momen sebanyak 53, $3 \%$. Sedangkan untuk responden yang memiliki pengetahuan baik namun tidak patuh melakukan handhygiene dalam 5 momen ada sebanyak 5,3\%, untuk responden yang memiliki pengetahuan tidak baik dan tidak patuh dalam melakukan hand hygiene 5 momen adalah sebanyak $46,7 \%$.

Hasil uji statistik diperoleh p-value sebesar 0,016 (lebih kecil dari nilai alpha $=0,05$ ) yang berarti Ha diterima sehingga disimpulkan ada hubungan yang bermakna (signifikan) antara hubungan pengetahuan infeksi nosokomial dengan kepatuhan handhygiene dalam 5 momen di ruang rawat inap RS. Mitra Husada. Dari hasil analisis juga diperoleh nilai $\mathrm{OR}=15,750$ artinya responden yang memiliki pengetahuan baik lebih patuh 15,75 kali lebih besar untuk melakukan handhygiene dalam 5 momen. 
Tabel. 6

Pengetahuan Infeksi Nosokomial Memiliki Hubungan terhadap Kepatuhan Prosedur HandHygiene Perawat Bidan

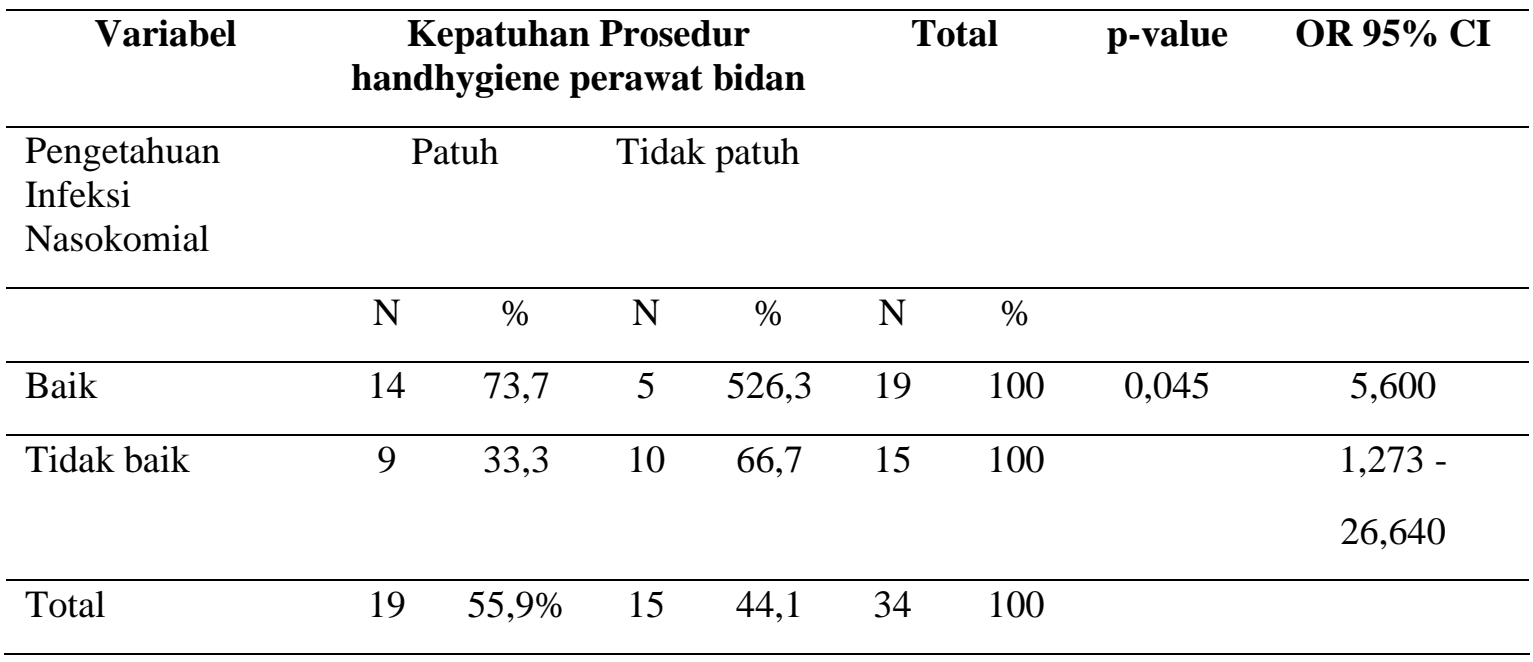

Sumber: Data Primer, 2017

Berdasarkan tabel 6 diatas diketahui bahwa ada sebanyak $73,7 \%$ responden yang memiliki pengetahuan yang baik dan patuh dalam melakukan prosedur handhygiene, sedangkan responden memiliki pengetahuan tidak baik dan tidak patuh dalam melakukan prosedur handhygiene sebanyak 33, 3\%. Sedangkan untuk responden yang memiliki pengetahuan baik namun tidak patuh melakukan prosedur handhygiene ada sebanyak 26,3\%, untuk responden yang memiliki pengetahuan tidak baik dan tidak patuh dalam melakukan prosedur handhygiene adalah sebanyak 66,7 $\%$. Hasil uji statistik diperoleh $p$-value sebesar 0,045 (lebih kecil dari nilai alpha $=0,05$ ) yang berarti Ha diterima sehingga disimpulkan ada hubungan yang bermakna (signifikan) antara hubungan pengetahuan infeksi nosokomial dengan kepatuhan prosedur handhygiene di ruang rawat inap RS. Mitra Husada. Dari hasil analisis juga diperoleh nilai $\mathrm{OR}=5,600$ artinya responden yang memiliki pengetahuan baik lebih patuh 5,6 kali lebih besar untuk melakukan prosedur handhygiene.

\section{PEMBAHASAN}

\section{Karakteristik Responden Berdasarkan Umur}

Hasil penelitian menunjukkan bahwa karakteristik responden di ruang rawat inap RS. Mitra Husada terdapat 20,6\% responden tahun dengan usia rata-rata responden 28 tahun. Umur berhubungan dengan usia kerja, kekuatan fisik dan kecerdasan intelektual maupun emosional. Kemampuan seorang perawat dalam berpikir kritis dalam 
melakukan asuhan keperawatan selama usia dewasa dengan banyaknya kasus yang diperoleh $^{12}$. Sesuai dengan penelitian sebelumnya yang menyatakan bahwa kinerja perawat dapat ditingkatkan jika perawat memiliki karakteristik responden berupa umur responden berada pada usia 25-34 tahun ${ }^{13}$. Pada penelitian ini, responden yang berumur 28 tahun terdapat sebanyak 20,6\%. Responden cenderung untuk lebih memenuhi standar yang ada dan memiliki tingkat pengetahuan yang lebih baik dikarenakan pada tingkat usia tersebut, seseorang memiliki kemampuan yang lebih untuk mengingat kembali (recall) materi yang telah dipelajari ataupun untuk mengimplementasikan pengetahuan atau materi yang dimiliki ${ }^{11}$.

\section{Karakteristik Responden Berdasarkan Jenis Kelamin}

Jenis kelamin yang paling banyak menjadi responden penelitian adalah laki-laki yaitu $(55,9 \%)$. Berdasarkan jenis kelamin pada umumnya dalam kepatuhan wanita lebih patuh daripada pria, karena wanita lebih patuh dan peduli untuk meningkatkan pelayanan ke pasien ${ }^{14}$. Pada penelitian ini perawat dengan jenis kelamin perempuan dan bidan cenderung lebih taat dan memenuhi standar yang ada dan cenderung lebih rajin dalam merawat diri sehingga praktik dalam pencegahan infeksi nosokomial lebih baik.

\section{Pengetahuan Perawat dan Bidan Tentang Infeksi Nosokomial}

Pada penelitian yang dilakukan oleh peneliti, hasil penelitian menunjukkan bahwa perawat bidan yang memiliki pengetahuan baik terhadap infeksi nosokomial adalah 55,9\%. Pengetahuan seseorang mempengaruhi praktik individu, yang mana makin baik pengetahuan seseorang maka makin baik pula praktik seseorang untuk melakukan pencegahan infeksi nosokomial. Pengetahuan adalah hasil penginderaan manusia/ hasil tau seseorang terhadap objek melalui indera yang dimilikinya seperti mata, hidung dan telinga ${ }^{9}$. Pengetahuan seseorang terhadap objek mempunyai intensitas atau yang berbedabeda. Pengetahuan perawat yang baik terjadi karena pengetahuan perawat sudah pada tahap memahami dan tidak hanya tau bahwa pencegahan infeksi nosokomial itu bermanfaat untuk mencegah penularan penyakit. Hasil penelitian ini sesuai dengan penelitian terdahulu yang menyatakan bahwa sebagian besar perawat yang menjadi responden memiliki pengetahuan yang baik ${ }^{10}$.

Hubungan pengetahuan infeksi nosokomial terhadap kepatuhan handhygiene perawat bidan dalam 5 momen dan kepatuhan prosedur handhygiene perawat bidan.

Hasil uji statistik hubungan pengetahuan infeksi nosokomial terhadap kepatuhan handhygiene perawat bidan dalam 5 momen diperoleh $p$-value sebesar 0,016 (lebih kecil dari nilai alpha $=0,05)$ yang berarti $\mathrm{Ha}$ 
diterima sehingga disimpulkan ada hubungan yang bermakna (signifikan) antara hubungan pengetahuan infeksi nosokomial dengan kepatuhan handhygiene dalam 5 momen di ruang rawat inap RS. Mitra Husada. Dari hasil analisis juga diperoleh nilai $\mathrm{OR}=15,750$ artinya responden yang memiliki pengetahuan baik lebih patuh 15,75 kali lebih besar untuk melakukan handhygiene dalam 5 momen. Sedangkan untuk hasil uji statistik hubungan pengetahuan infeksi nosokomial terhadap kepatuhan prosedur handhygiene perawat bidan diperoleh $p$-value sebesar 0,045 (lebih kecil dari nilai alpha $=0,05$ ) yang berarti $\mathrm{Ha}$ diterima sehingga disimpulkan ada hubungan yang bermakna (signifikan) antara hubungan pengetahuan infeksi nosokomial dengan kepatuhan prosedur handhygiene di ruang rawat inap RS. Mitra Husada. Dari hasil analisis juga diperoleh nilai $\mathrm{OR}=5,600$ artinya responden yang memiliki pengetahuan baik lebih patuh 5,6 kali lebih besar untuk melakukan prosedur handhygiene.

Pengetahuan seseorang mempengaruhi praktik individu, yang mana makin baik pengetahuan seseorang maka makin baik pula praktik seseorang untuk melakukan pencegahan infeksi nosokomial. Pengetahuan adalah hasil penginderaan manusia/ hasil tau seseorang terhadap objek melalui indera yang dimilikinya seperti mata, hidung dan telinga ${ }^{11}$. Pada penelitian terdahulu menyatakan bahwa ada hubungan antara pengetahuan perawat dengan pelaksanaan prosedur universal precaution perlu diketahui karena apabila tingkat pengetahuan seorang perawat tersebut kurang maka dapat menimbulkan hal-hal yang membahayakan bagi diri sendiri maupun bagi pasien ${ }^{13}$. Hasil penelitian ini berbeda dengan penelitian terdahulu yang menyatakan bahwa tidak ada hubungan antara pengetahuan perawat tentang infeksi nosokomial terhadap kepatuhan handhygiene perawat ${ }^{7}$.

Dalam penelitian yang dilakukan oleh peneliti, semakin baik pengetahuan perawat maka semakin baik pula kepatuhan perawat dalam melaksanakan handhygiene dalam 5 momen. Hal ini dikarenakan dengan pengetahuan yang dimiliki perawat diharapkan perawat menyadari pentingnya pencegahan infeksi nosokomial. Sedangkan perawat dan bidan yang pengetahuannya baik namun tidak patuh dalam melaksanakan handhygiene dalam 5 momen disebabkan karena pengetahuan perawat baru pada tahap tahu dan belum memahami sehingga belum secara sunguh-sungguh melakukan handhygiene dalam 5 momen dan melakukan handhygiene sesuai dengan prosedur.

\section{KESIMPULAN}

Ada hubungan yang bermakna (signifikan) antara pengetahuan infeksi nosokomial dengan kepatuhan prosedur handhygiene di ruang rawat inap RS. Mitra Husada. 


\section{SARAN}

Peneliti berharap upaya untuk meningkatkan kepatuhan handhygiene khususnya bagi para perawat dan bidan melalui edukasi dan promosi yang dilakukan secara rutin dan berkala oleh PPI rumah sakit dengan harapan kepatuhan handhygiene dalam 5 moment perawat bidan dan prosedur handhygiene dalam upaya pencegahan infeksi nosokomial dapat meningkat.

\section{DAFTAR PUSTAKA}

1. Ahmad,K. 2010. Kunci pengendalian infeksi nosokomial. Padang: angkasa raya.

2. Akyol, A.D. 2009. Handhygiene among nurses in Turkey: opinions and practices. Diakses pada tanggal 7 November 2016 pada pukul 15.00 WIB.

3. Budiarto, Eko. 2009. Metodologi Penelitian Kedokteran. Jakarta: EGC

4. Darmadi. 2009. Infeksi Nosokomial, Problematika, dan Pengendaliannya. Jakarta: Salemba Medika.

5. Departemen Kesehatan Republik Indonesia. 2009. Pedoman Manajerial Pencegahan dan Pengendalian Infeksi di Rumah Sakit dan Fasilitas Pelayanan Kesehatan Lainnya. Jakarta : Departemen Kesehatan RI.
6. Hasmoko, E.V. 2008. Analisis faktorfaktor yang mempengaruhi kinerja klinis perawat berdasarkan penerapan sistem pengembangan manajemen kinerja klinis (Spmkk) di ruang rawat inap rumah sakit Panti Wilasa Citarum, Semarang 2008. Thesis. Program Pascasarjana Universitas Diponogoro Semarang.

7. Jamaludin, J, Sugeng, S, Wahyu,I, dan Sondang, M. 2012. Kepatuhan Cuci Tangan Momen di Unit Perawatan Intensif. Majalah Kedokteran Terapi Intensif.

8. Karabay, Oguz, dkk. 2009. Compliance and Efficacy of Hand Rubbing during In hospital Practice. Jakarta: Penerbit EGC.

9. Notoadmojo,S. 2010. Metodologi penelitian kesehatan. Jakarta: Rineka Cipta.

10. Nursallam. 2009. Konsep dan penerapan metodologi penelitian ilmu ilmiah keperawatan. Jakarta: Penerbit Salemba Medika.

11. PERDALIN. 2010. Handout pengendalian infeksi nosokomial. Jakarta.

12. Pittet,D. 2011. Improving Adherence to Hand Hygiene Practice: A Multidisciplinary Approach. Emerging Infecctious Diseases.

13. PPIRS. Mitra Husada. 2015. Survey INOS dan Kepatuhan Hand Hygiene. Pringsewu: TIM PPI RS. Mitra Husada. 
Wacana Kesehatan, Volume 5, No. 1, Juli 2020 